\title{
O 'espaço' da arte contemporânea em contextos educativos: confluências e interferências sócio-culturais ${ }^{1}$
}

Kelly Bianca Clifford Valença²

\section{Resumo}

Este trabalho investiga o modo como seis alunos do curso de Licenciatura em Artes Visuais da Faculdade de Artes Visuais (FAV) da Universidade Federal de Goiás (UFG), compreendem e se relacionam com imagens da arte contemporânea como objeto de ensino. Inspirada na minha observação sobre a resistência ao uso destas imagens em salas de aula, esta pesquisa se configura como uma mostra de dados que constrói uma trama de opiniões que ora se entrecruzam, ora divergem, mas, sobretudo, refletem questões pedagógicas e sócio-culturais naturalizadas nas compreensões e concepções destes futuros professores. Uma metodologia qualitativa desenvolvida através de entrevistas individuais e grupos focais orientou esta investigação que considera imagens, falas, silêncios, gestos e reações como partes integrantes de uma análise crítica e construtiva de relatos que dialogam com a cultura visual.

Palavras-chave: arte contemporânea, ensino de arte, cultura visual.

\section{Abstract}

This work investigates the way how six students attending the Visual Arts Teaching Program at the Visual Arts College of the Federal University of Goiás, understand and interrelate with contemporary art images as their teaching object. Inspired on my observations concerning the resistance to the use of these images in classrooms, this research constitutes a sample of collected data that builds a net of point of views that sometimes overcross, sometimes diverge, but, especially, reflect pedagogical, social and cultural issues naturalized in the understandings and conceptions of those future teachers. Developed through individual interviews and focal groups, this investigation is oriented by a qualitative methodological perspective which considers images, talks, silences, gestures and reactions as part of a critical and constructive analysis of narratives that dialogue with visual culture.

Key-Words: contemporary art, teaching art, visual culture.

O meu interesse por esse tema de estudo teve início em 2003 quando, ao desenvolver uma pesquisa em Recife com professores de artes das redes pública e particular, percebi que a arte contemporânea não era abordada pelos mesmos em salas de aula.

Esses resultados me intrigaram de tal maneira que adotei a problemática como tema de minha dissertação de Mestrado em Cultura Visual (VALENÇA, 2009) cujo objetivo

\footnotetext{
${ }^{1}$ A pesquisa em pauta foi realizada durante os anos de 2007 e 2008 e é resultado da minha dissertação de Mestrado em Cultura Visual (UFG), defendida e aprovada em 2009. Neste contexto, o artigo aqui tratado resume e problematiza questões específicas da análise dos resultados obtidos nesse percurso de modo a discutir o papel docente frente a arte contemporânea.

${ }^{2}$ Professora efetiva da Universidade Federal de Goiás / Centro de Ensino e Pesquisa Aplicada à Educação (CEPAE). Mestre em Cultura Visual pela mesma Universidade.
} 
consistiu em investigar o modo como seis alunos da Licenciatura em Artes Visuais da UFG - futuros docentes - lidavam e compreendiam a arte contemporânea. Vale ressaltar que a contemporaneidade que me refiro neste trabalho não é aquela recorrente em sites e livros de história e história da arte (VICENTINO, 2002; COTRIM, 2007; www.historiadaarte.com.br) que contempla o período do século XX aos nossos dias, mas, "(...) arte que está empenhada no aqui e no agora" (THISTLEWOOD, 2005, p. 115), ou ainda, a arte do tempo em que vivemos conforme Oliveira e Freitag (2008). Assim, chamo de arte contemporânea neste estudo, obras, imagens e conceitos do nosso tempo, em termos de produção e práticas artísticas. Ao mencionar 'nosso tempo', refirome ao tempo em que vivemos. Falo do que é produzido em nossos dias e que, em minha trajetória docente até aqui percorrida, percebi não ser comumente levado às salas de aula. Em lugar disso, as obras de arte que tenho observado serem trabalhadas, como sendo de arte contemporânea, são, em sua maioria, obras do período modernista unicamente.

\section{Escolhas e procedimentos de um percurso cheio de inquietudes}

Por intentar investigar a relação de alunos da Licenciatura em Artes Visuais da UFG com a arte contemporânea - e isso implica em experiências vividas (DENZIN; LINCOLN, 2006) - julguei pertinente que o desenvolvimento desse trabalho constituísse uma pesquisa preponderantemente qualitativa, integrando entrevistas individuais e grupos focais auxiliados através do uso de imagens trazidas pelos alunos e registros realizados no diário de campo.

A propósito, uma pesquisa qualitativa,

Consiste em um conjunto de práticas materiais e interpretativas que dão visibilidade ao mundo. Essas práticas transformam o mundo em uma série de representações, incluindo as notas de campo, as entrevistas, as conversas, (...) as gravações e os lembretes (DENZIN; LINCOLN, 2006, p. 17).

Considerar uma pesquisa unicamente quantitativa ou qualitativa, no entanto, parece-me algo difícil de se conceber na prática. Por isso, preocupei-me fundamentalmente, não exclusivamente, em pensar os dados de modo qualitativo. Isso pressupõe uma gama de respostas e reações ricas e complexas, onde o principal objetivo não deve ser "(...) contar opiniões ou pessoas, mas ao contrário, explorar o espectro de opiniões [e] as diferentes representações sobre o assunto em questão" (GASKELL, 2004, p. 68).

Optei então, por entrevistar alunos de diferentes semestres do curso configurando três duplas - um homem e uma mulher em cada dupla - sendo uma do primeiro, uma do terceiro e a outra do sétimo período. Essa escolha refletiu o desejo de entrevistar alunos 
que estivessem em diferentes etapas da formação, ou seja, no início, meio e fim do curso.

Já a opção por trabalhar com homens e mulheres proporcionalmente, derivou do fato de não desejar que houvesse, nas entrevistas e grupos focais, o predomínio de um gênero em detrimento do outro. Objetivava discutir como a arte contemporânea era compreendida pelos colaboradores dessa pesquisa; como suas experiências com arte contemporânea durante o curso se aproximavam, se contrastavam e, ou, ainda, como elas se transformavam em relação aos diferentes períodos da graduação.

Afinal, eram os estudantes desse curso que estavam sendo preparados para atuar em sala de aula.

Acredito, com essa experiência, ter conseguido despertar nos colaboradores algumas reflexões no que tange à arte contemporânea em contextos pedagógicos.

\section{Tecendo um breve diálogo com os resultados}

Após a realização das entrevistas individuais e grupos focais, uma vasta gama de gravações foi transcrita, revisada, selecionada e, por fim, analisada.

Destarte, concebi as questões que descreverei a seguir como os principais pontos de discussão da análise de modo a considerar para tal escolha, os critérios de recorrência, vigor e pertinência à pesquisa em pauta perante os dados obtidos.

- Apesar de muitos dos colaboradores se referirem à arte contemporânea como algo que eles 'gostassem', a impressão que mais me impactou através de vários trechos dos relatos, é a de que a sensação de rechaço a esta arte se sobrepõe à satisfação que ela possa gerar.

É curiosa essa repulsa já que o enfoque do curso de Licenciatura em Artes Visuais da FAV - UFG é, explicitamente, em arte contemporânea. Um dado que reforça essa condição é o fato de ter sido recentemente extinto o teste de aptidão (prova específica) que integrava o vestibular. Tal teste compreendia dois tipos de desenho (criação e observação) e foi abolido porque os professores entenderam que essa exigência - saber desenhar - não cabia nos propósitos e interesses do curso.

A questão cultural, de acesso, mas também, de valores e concepções em torno da arte contemporânea, me parece ser o foco primordial dessa relação oscilante entre os 
colaboradores e a temática aqui tratada. Valores e concepções referentes à noção de beleza, harmonia, simetria e até mesmo de interpretação, precedem e acompanham o processo de formação desses alunos. De tal forma isso é forte, que tendo a compreendêlas como questões enraizadas e naturalizadas culturalmente. Apesar de o curso ter uma ênfase em arte contemporânea, a questão cultural parece prevalecer a ponto de interferir na formação docente desses alunos. Diálogos, tempo e reflexão sobre o assunto se configuraram como importantes contribuições nesse processo.

- A maioria dos colaboradores não tinha a prática de freqüentar museus até a época do início desta coleta dos dados.

É possível vincular a ausência dessa prática à resistência que percebi, por parte dos alunos, em relação à arte contemporânea. Pelos relatos coletados acredito que tal ausência denotou, ainda, uma falta de interesse ou mesmo um não "gostar", apesar da justificativa mais recorrente ter sido a falta de tempo.

- A concepção de arte apresentada por alguns colaboradores era freqüentemente associada à beleza.

De fato, esse ideal de beleza tão recorrente nas falas dos colaboradores teve origem na antiguidade clássica quando elementos já mencionados como proporção, figuração, siemetria e harmonia constiuíam subsídios basilares a toda e qualquer obra de arte. Tal concepção, apesar de colidir com a arte contemporânea, ainda hoje parece perdurar e, por isto, ser a principal causa da repulsa que observei nos sujeitos dessa pesquisa.

- A diferença de concepções apresentada pelos seis alunos não necessariamente sofreu uma variação gradativa conforme a mudança de períodos (semestres I, III e VII).

Apesar da manifestação de resistência à arte contemporânea dos alunos dos I e III períodos ter sido mais intensa, a questão cultural de valores e concepções se distribuiu de forma quase indiferenciada e bastante diversificada em relação aos colaboradores dos três períodos. Também vale notar que vi negadas as minhas expectativas de que os estudantes do sétimo período seriam mais participativos ou teriam uma maturidade conceitual diferenciada. Tanto houve aluno do I quanto do VII período que limitavam suas manifestações a reduzidas interações com os colegas. Tanto lidei com aluno do I período que apresentou uma concepção de arte contemporânea voltada para os dias em que vivemos como lidei com aluno do VII período que compreendia a arte contemporânea como sendo o modernismo. 


\section{Análises e discussões na perspectiva da Cultura Visual}

Campo de estudo recente, discussões acerca da cultura visual no Brasil ainda se configuram como novidade para muitos. Nessa perspectiva, imagens, artísticas ou não, são tratadas como artefatos culturais, logo, passíveis de diversas interpretações. Assim, a cultura visual se propõe a romper com sistemas pré-estabelecidos de interpretação na expectativa de que novos significados sejam construídos (MARTINS, 2007a).

Trabalhar a partir de uma abordagem cultural implica considerar o ato de interpretação como algo construído histórica, social e culturalmente.

Dos seis colaboradores dessa pesquisa, dois já haviam tido experiências em salas de aula atuando como professores de arte, contudo, nunca haviam abordado a arte contemporânea. Neste contexto, por que imagens de arte contemporânea bem como o próprio assunto, são pouco levados - quando levados - às salas de aula? Segundo Richter (2003), nessas obras, "os elementos formais aparecem como meios através dos quais o conteúdo artístico é revelado, e não como o próprio conteúdo. A ênfase é dada aos temas, as idéias, aos aspectos sociais, políticos (...)" (pp. 48-49).

Com base nesses questionamentos, de que forma a ausência da arte contemporânea nas salas de aula pode se relacionar com a dificuldade de trabalhar a partir de múltiplas interpretações, flexíveis e exploratórias? Uma condição que se vincula a esse posicionamento crítico e aberto face a interpretação é a autoridade daqueles que estariam aptos a poder fazê-la. Além da oferta de uma literatura que privilegia e valoriza obras de arte figurativas, ainda temos um frágil acervo teórico de interpretações sobre obras contemporâneas que não recaem nessa categoria.

Afinal, não é através dos olhos, discursos e escritos de outros que estamos acostumados a ver? Sem muitas vezes pararmos para pensar que os discursos legitimados como verdade, em sua maioria, são constituídos por relações de poder tendenciosas a nos distanciar do fato de que

O papel que arte e imagem desempenham na cultura e nas instituições educacionais não é refletir a realidade ou torná-la mais real, mas, articular e colocar em cena uma diversidade de sentidos e significados. Indivíduos de um mesmo grupo ou comunidade podem conviver com as mesmas imagens, mas cada um as vive e interpreta de maneira diferente, criando brechas e espaços de diversidade. As resistências à concepção inclusiva da cultura visual e ao princípio da diversidade de interpretações - dificuldades centrais na relação indivíduo arte/imagem - se manifestam 
através de grupos hegemônicos que aspiram impor e autorizar suas interpretações, seu nível de verdade, constrangendo professores, alunos e até mesmo pesquisadores a aceitá-las ou a lutar para libertá-las do habitus acadêmico (MARTINS, 2007b, p. 74).

Acredito que a dificuldade de se trabalhar imagens de arte contemporânea em contextos educacionais, tem relação direta com o fato dessas obras gerarem inquietações face aos padrões visuais propostos - ou, por que não dizer impostos - por grupos hegemônicos, conforme discute Martins (Ibid.). Além disto, em geral, muitos dos autores dessas obras ainda estão vivos, nem sempre dominam técnicas como desenho e pintura e, para completar o cenário, ganham fama - quando ganham - em seguimentos particulares e regionalizados do circuito artístico. Como se não bastasse, vale a pena refletir sobre o fato de que boa parte desses trabalhos são intitulados "Sem título". Neste sentido, imagens da produção contemporânea de arte dificilmente insinuam ou induzem a um discurso construído que, indiscutivelmente, tende a canonizar e condicionar certas interpretações.

Outra reflexão necessária e de importância fundamental nesta discussão, diz respeito à formação docente em arte. Em boa parte das instituições de nosso país, ainda hoje, "leituras" imagéticas fixas, objetivas e unidirecionais de obras de artistas famosos (de preferência que já tenham morrido), são práticas que encontram grande aceitação. Assim, como esperar que professores reajam ao se depararem com uma imagem que foi realizada 'mês passado', por 'fulano de tal', 'sem título' e cujo 'discurso' não se encontra pré-estabelecido em livro algum? É compreensível que, no mínimo, esse docente não cogite a possibilidade de levar tais imagens para o contexto da sala de aula. Contudo, apesar de compreensível, não abordar a arte produzida em nossos dias, é negar aos alunos a possibilidade de estar em sintonia com o tempo em que vivem.

Numa perspectiva cultural, o termo 'leitura' não só implica na existência de uma interpretação correta como reafirma que

Ao tentar definir ou delimitar um repertório de manifestações, objetos e imagens a ser estudado e a ser feito e construído na educação do ver, instituições religiosas, políticas educacionais e acadêmicas estabelecem juízos e valores estéticos que representam perspectivas unilaterais com a pretensão de criar regras que influenciem - muitas vezes sem melhorar - a experiência visual dos indivíduos (MARTINS, 2007a, p. 18).

Assim, a dificuldade de conceber obras de arte como passíveis de diversos modos de ver/interpretar, configura uma visão de arte e de interpretação que encontra-se 
enraizada em concepções modernistas (RICHTER, 2003). No caso, visões que ignoram o fato de que "não existe uma única verdade interpretativa (...) o que existem, são múltiplas comunidades interpretativas, cada qual com seus próprios critérios para avaliar uma interpretação" (DENZIN; LINCOLN, 2006, p. 37).

Abordar a arte de nosso tempo em contextos pedagógicos requer trabalho, empenho e, sobretudo, desconstruções. Antes de qualquer coisa, requer profissionais mais engajados social, política e culturalmente.

Assim, partindo da premissa de que a idéia de arte está vinculada à expressão de um povo, cultura e momento histórico, me parece coerente trabalhar com arte contemporânea, uma vez que "grande parte do que se produz hoje, no cenário artístico está em consonância com os conflitos e com a realidade que presenciamos diariamente, realidade esta que não podemos ignorar" (OLIVEIRA; FREITAG, 2008, p. 118). Isto é, ao pensar em tais imagens como representações de nosso momento histórico, elas, sem dúvida ganham outro sentido. "Repensar, a partir de outro ângulo, alguns dos problemas mais espinhosos deste momento cultural" (HERNÁNDEZ, 2007, p. 45) me parece não apenas necessário, mas, imprescindível a um ensino de arte crítico e construtivo. Não pretendo com isso, aludir qualquer expressão de arte contemporânea aos fatos e acontecimentos negativos, absurdos e, ou, repugnantes assistidos com freqüência na pós-modernidade. Nem tão pouco pretendo excluir tais situações dessa associação entre os diferentes sentidos que as representações podem ganhar nos diversos momentos históricos em que são geradas, circuladas ou interpretadas.

Colocando de outra maneira, acredito que um fator que também contribui com a dificuldade em relação à arte contemporânea, advém das possibilidades extremas que ela, muitas vezes, requer, tanto no seu processo de realização quanto no seu processo de exposição.

Vale relembrar a resistência que se instaura, desde muito cedo, quando somos condicionados a acreditar na existência de interpretações 'corretas' e 'universais'. Entretanto, através da nossa formação podemos iniciar um processo de questionamento sobre 'quem estabelece' o modo correto de interpretar. O adestramento que nosso olhar, via de regra, desde cedo é submetido, parece não dar vez à possibilidade da existência de múltiplas perspectivas de visão. Isso não denota necessariamente nossa posição de vítimas perante o sistema, mas, sobretudo, a necessidade de uma educação orientada para essas questões. 


\section{Arte contemporânea na escola: possibilidades e desafios}

O visual é composto por tudo o que vemos. Apesar disto incluir imagens, não as faz exclusivas. As imagens são parte dos artefatos de nossa sociedade, do mesmo modo que objetos como obras de arte também o são.

Certa vez, fui contestada numa apresentação de trabalho em evento nacional com a seguinte observação: 'Mas as obras de arte trazem consigo um discurso!' Sim, sei da existência de discursos de curadores e críticos, que por sinal, muitas vezes, em nada convergem com o discurso do artista que criou a obra e que, mesmo assim, são tratados como verdades fixas e absolutas. Além disso, quando o discurso do curador ou crítico se aproxima do discurso do artista, não significa que tal forma de ver e interpretar seja a única possível. Efland; Freedman e Stuhr, (2003) fortificam o exposto ao lembrarem que

(...) os espectadores de uma obra de arte a interpretam (...) a partir de perspectivas tão distintas que a partir de suas experiências visuais constroem de fato obras diferentes que podem chegar a parecer-se pouco ou nada com a intenção original do artista (p. 74) ${ }^{3}$.

É preciso que não confundamos imagem ou obra de arte com discurso. Os significados não estão nos artefatos. Estes, não carregam discursos de forma que as pessoas possam olhar e "alcançar" ou, ainda, adivinhar o que o artista quis "passar" ou dizer. Os discursos e significados estão nos sujeitos e em suas respectivas relações com os artefatos. Muito embora os artistas tenham intenções ao elaborarem seus trabalhos, isto não garante que as pessoas percebam em consonância com o pensamento do criador, nem tão pouco significa que este pensamento elimine outras maneiras de interpretar. São os olhos de outros que irão interagir com as obras, o que vai muito além da visão física. É assim que entram em cena nossos sentidos e repertórios. A relação de cada indivíduo com as imagens e/ou obras de arte é que constrói significado para as mesmas.

Por vivermos numa cultura escolar e acadêmica que preconiza a existência de um modo correto de "ler" imagens, com freqüência me deparo com pessoas que não se julgam aptas a falar sobre arte contemporânea, tendendo a compreendê-la como sendo algo para "iniciados" (ROUGE, 2003).

\footnotetext{
${ }^{3}$ (...) los espectadores de una obra de arte la interpretan o leen desde perspectivas tan distintas que a partir de su experiencia visual construyen de hecho obras diferentes que pueden llegar a parecerse poco o nada a la intención original del artista (EFLAND, FREEDMAN e STUHR 2003, p. 74).
} 
Deste modo, educar visualmente na perspectiva da cultura visual, requer espaço suficiente para que uma multiplicidade de olhares tenha vez no processo de interpretação de imagens. Nesta abordagem de trabalho, as interpretações de alunos, por exemplo, podem ser colocadas lado a lado às interpretações de qualquer professor, curador, crítico ou artista.

Em aulas de arte, é comum a situação de estudantes que, antes mesmo de terem oportunidade e tempo de se relacionar com imagens de obras artísticas, são induzidos pela fala de professores que expõem ou questionam os títulos dos trabalhos, bem como os anos, nomes dos artistas que os produziu além de interpretá-los conforme suas opiniões pessoais ou discursos de algum crítico ou historiador de arte. Perguntas como

(...) o que vemos? Que significados quis passar o autor? Quando foi feito? (...) são as perguntas que os educadores têm proposto para os alunos ou para os visitantes de exposições, guiados por uma concepção da história da arte que considera a representação visual como dotada de uma verdade que a educação há de desvelar (HERNÁNDEZ, 2007, p. 55).

Embora pareça algo simples e corriqueiro, ao trabalhar essas imagens de modo a expor interpretações ou comentários prévios, como exibir títulos e nomes de artistas geralmente famosos - abortamos a oportunidade de que a subjetividade de cada aluno seja manifestada e, por conseguinte, diferentes modos de ver venham à tona. Desta maneira, perde-se a chance do espaço de autoria dos estudantes. A esse respeito Martins (2007a), comenta que

O conceito de autor se combina com o conceito de interpretação porque cada vez que se interpreta uma imagem está sendo construída uma forma de autoria. Tal deslocamento se deve, por um lado, ao distanciamento da noção metafísica de unidade, ou seja, da idéia de interpretação única, autorizada e reconhecida, e por outro, à multiplicidade de discursos e interpretações da arte e da imagem que geram mobilidades na posição de sujeito (p. 73).

Trabalhar imagens numa perspectiva cultural, portanto, não implica em ocultar nomes de artistas e títulos de obras, mas de saber como e quando contextualizá-los. Ao trazer essas informações após o espaço de aprendizagem ter favorecido diversas reações, silêncios e vozes "(...) que têm sido historicamente sufocadas (...)" (DENZIN; LINCOLN, 2006, p. 128), estaremos proporcionando um ambiente dialógico e inclusivo que pode deixar emergir outras interpretações em sintonia com as vivências e repertório dos alunos. 
Com base no exposto, percebo na arte contemporânea um instrumento didático excepcional devido seu caráter fundamentalmente subjetivo em lugar da figuração tão predominante em outros tempos. Acredito que esta subjetividade apresenta relações estreitas com a cultura visual porque abre espaço para diferentes interpretações. Mediar esse processo para que a aprendizagem de nossos alunos seja significativa, sem dúvidas é um desafio que merece pesquisa, criticidade e empenho de nossa parte.

\section{Últimas considerações}

Uma de minhas expectativas com o desenvolvimento dessa pesquisa é que a mesma, de algum modo, suscite outras idéias contribuindo ou complementando a formação docente na área de arte. De certo, a participação, envolvimento e boa vontade dos colaboradores desse trabalho representaram a busca por um ensino de arte crítico e inclusivo. Além disso, percebi que o envolvimento deles com esta investigação, pode ter contribuído, de alguma forma, para uma reflexão sobre o modo de lidar, olhar e, até mesmo pensar a arte contemporânea.

Atualmente, a maior parte dos colaboradores está trabalhando com ensino de arte e, segundo eles, imagens de arte contemporânea estão sendo utilizadas nas aulas, prática que não era cogitada antes da participação deles na pesquisa.

Além da expectativa comentada, também guardo o desejo de que as imagens de arte contemporânea possam ser abordadas em contextos educativos com um enfoque crítico e cultural. Este enfoque poderá colocar alunos e professores, isto é, diferentes "comunidades de discursos" (HERNÁNDEZ, 2007, p. 81) frente a situações que dizem respeito ao nosso tempo e que, por extensão, possam contribuir para uma educação que insira os alunos em questões e problemas cotidianos visando compreendê-los e transformá-los.

\section{Referências}

COTRIM, Gilberto. História global: Brasil e geral. São Paulo: Saraiva, 2007.

DENZIN, Norman; LINCOLN, Ivonna. O planejamento da pesquisa qualitativa: teoria e abordagens. Porto Alegre: Artmed, 2006.

EFLAND, A.; FREEDMAN, K.; STUHR, P. Teoria Posmoderna: Cambiar concepciones del arte, la cultura y la educíon. In: La educación en el arte posmoderno. Barcelona: Paiós, 2003, pp.39-98.

HERNÁNDEZ. Fernando. Catadores da cultura visual: proposta para uma nova narrativa educacional. Porto Alegre: Editora Mediação, 2007. 
GASKELL, George. Entrevistas individuais e grupais. In: GASKELL, George e BAUER Martin. Pesquisa qualitativa com texto imagem e som: um manual prático. Petrópolis: Vozes, 2004, pp. 64-113.

MARTINS, Raimundo. A cultura visual e a construção social da arte, da imagem e das práticas do ver. In: OLIVEIRA, Marilda (org.). Arte, educação e cultura. Santa Maria: Editora da UFSM, 2007a, pp. 18-40.

MARTINS, Raimundo. Porque e como falamos da cultura visual? Visualidades - Revista do programa de Mestrado em Cultura Visual. Goiânia, v. 4, n. 1 e 2, pp. 65-79, dez. 2007b.

OLIVEIRA, Marilda; FREITAG, Vanessa. A produção contemporânea como espaço de conflito no ensino de artes. Raimundo Martins (Org.). Visualidade e Educação. Goiânia: FUNAPE/Programa de Pós Graduação em Cultura Visual, n. 3, pp. 117-130, 2008.

RICHTER, Ivone. Interculturalidade e estética do cotidiano no ensino das artes visuais. Campinas: Mercado de Letras, 2003.

ROUGE, Isabelle de Maison. A arte contemporânea. Lisboa: Inquérito, 2003.

THISTLEWOOD, David. Arte contemporânea na educação: construção, dês-construção, re-construção, reações dos estudantes britânicos e brasileiros ao contemporâneo. In:

BARBOSA, Ana Mae (org.). Arte educação contemporânea: consonâncias internacionais. Tradução: Martin Grossmann e Maria Inês Amoroso. São Paulo: Cortez, 2005, pp. $113-125$.

VALENÇA, Kelly. Arte contemporânea na formação de professores: um estudo com alunos da Licenciatura em Artes Visuais da UFG. 2009. 113 p. Dissertação (Mestrado em Cultura Visual) - Faculdade de Artes Visuais, Universidade Federal de Goiás, Goiânia, 2009.

VICENTINO. Cláudio. História geral. São Paulo: Scipione, 2002. 